\title{
Family planning use among young mothers in the peri-urban area of Osun State, Nigeria: the influence of spousal communication and attitude
}

\author{
Obasanjo Afolabi Bolarinwa \\ Department of Public Health Medicine, University of KwaZulu-Natal, \\ Durban, South Africa \\ Akintayo Taiwo Olaniyan \\ Demography and Social Statistics, Obafemi Awolowo University, Ile-Ife, Nigeria \\ Balsam Qubais Saeed \\ Clinical Sciences, College of Medicine, University of Sharjah, \\ Sharjah, United Arab Emirates, and \\ Olalekan Seun Olagunju \\ Demography and Social Statistics, Obafemi Awolowo University, Ile-Ife, Nigeria
}

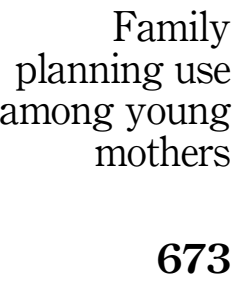

Received 27 November 2020 Revised 9 February 2021 10 February 2021 Accepted 30 March 2021

\begin{abstract}
Purpose - The purpose of this study is to examine the influence of spousal communication and attitude toward family planning (FP) use among young mothers in the peri-urban area of Osun State, Nigeria.

Design/methodology/approach - The study was limited to a primary cross-sectional dataset collected among 420 young mothers between the ages of 15 and 30 years residing in the peri-urban area of Osun State, Nigeria. The distribution of the use of FP across the socio-demographic, spousal communication and attitude was described, and multivariate logistic regression was used to assess FP use likelihood. The results were presented as crude odds ratios (cOR) and adjusted odds ratios (aOR) with their corresponding 95\% confidence intervals. Statistical significance was set at $p$-value $<0.05$.

Findings - FP use were more likely to be higher among the respondents whose male spouses have good communication $[\mathrm{cOR}=35.5 ; 95 \%(15.93-78.99)]$, good attitude $[\mathrm{cOR}=8.695 \%(3.59-20.65)]$ and this persisted after adjusting for significant covariates $[\mathrm{aOR}=80.7 ; 95 \%(19.80-328.84)]$ and $[\mathrm{aOR}=5.495 \%(1.34-22.17)]$. Research limitations/implications - The study's strength is the ability to design questionnaires tailored toward the literature gap on nonuse of FP by young mothers. However, the study is without limitation because the focus was on young mothers alone why their spouses were not interviewed. Male spouse details were collected from the young mothers, and there may be inaccuracy in the reporting of male spouse sociodemographic characteristics used as a control variable in this study. Also, because this research was conducted among specific group, the results of the study cannot be used to generalize for other group.

Practical implications - Future studies should consider both partners to harness the true picture of poor communication and attitude toward each other. The future study will also be more robust if it can consider a
\end{abstract}

(C) Obasanjo Afolabi Bolarinwa, Akintayo Taiwo Olaniyan, Balsam Qubais Saeed and Olalekan Seun Olagunju. Published in Journal of Health Research. Published by Emerald Publishing Limited. This article is published under the Creative Commons Attribution (CC BY 4.0) licence. Anyone may reproduce, distribute, translate and create derivative works of this article (for both commercial and noncommercial purposes), subject to full attribution to the original publication and authors. The full terms of this licence may be seen at http://creativecommons.org/licences/by/4.0/legalcode

Funding: No specific funding was received for this research.

Availability of data and materials: De-identified dataset used for this research work will be provided upon request

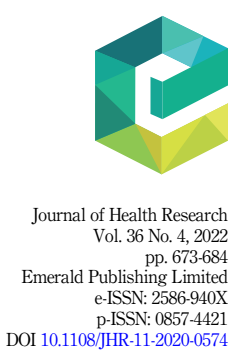


JHR

36,4

\section{4}

qualitative research design as this will help unveil more underlining factors influencing the nonuse of FP among young mothers.

Originality/value - Young mothers with good spousal communication and attitude were more likely to use FP. Deliberate interventions should include focus group discussion and community sensitization to encourage good communication and attitude of male spouse toward their partner in the peri-urban area of Osun State, Nigeria.

Keywords Spousal communication, Spousal attitude, Family planning use, Young mothers, Peri-urban area, Nigeria

Paper type Research paper

\section{Introduction}

A significant factor underlying high birth rates in sub-Saharan Africa (SSA) is the low use of family planning $(\mathrm{FP})$, leading to an estimated 35 million women in SSA having an unmet need for $\mathrm{FP}[1]$. In the same vein, unsafe abortions account for about $14 \%$ of maternal deaths on the continent [2], and roughly $51 \%$ of global maternal deaths involved African women aged from 15 to 29 years [3], with total fertility rates (TFRs) of around five births per woman of reproductive age in SSA [4]. Consistent utilization of FP methods has the full potential to decrease excessive birth rate and maternal mortality rates [4].

Impressive global gains have been made in recent decades in improving contraceptive prevalence rates and decreasing fertility rates. At the same time, increasing numbers of men and women in developing countries willing to adopt FP and exercise their right to freely decide their children's number and spacing [5].

Initially, women were the primary target for FP. However, there is a growing recognition that reproductive health is a joint responsibility of men and women, and several studies have reported that men are vital persons in the reproductive decision-making process and their decisions have profound influences on women's health [2,3], failure in involving men in FP programs can hamper the contraceptive use of women even if they are educated and motivated because of opposition from their spouses [6].

It has been reported that interventions to promote men's involvement in FP use have yielded some positive results in other low-income countries [7]. However, this concept is yet to be fully explored in Nigeria. Men are perceived as significant barriers to FP use in some communities, and lack of spousal communication regarding contraception being evident in studies conducted in South West and Northern Nigeria [2].

Lack of access to reproductive health services among young women is associated with an increased risk of unplanned pregnancy and early school dropout due to pregnancy. Access to FP services remains an issue for young women and men because of cultural, medical and financial barriers, and this has also been stressed in the past [8].

A study in Ghana discovered that spousal agreement to the use of FP methods was crucial to the success of any FP intervention [2], concurrence-agreement between partners developed through couples openly discussing fertility preferences and desires increases the likelihood of contraceptive use [9].

Health education has also been noted as one of the major driving forces in communication either at the interpersonal, group, cultural or societal level; effective interpersonal communication skills are essential ingredients for a healthy social relationship within a spousal relationship [8].

Spousal communication encourages FP methods such that $79 \%$ of women who discussed with their partners use the FP method [2]. Several studies have shown that spousal communication can increase contraceptive uptake and continuation [8]. Partner's agreement is a reliable predictive of positive on women's reproductive health outcomes [10]. Spousal communication about fertility and family planning in Africa is quite low, and more exceptional communication may increase the accuracy of a spousal perception of FP use [11]. 
Despite the government's and health workers' efforts at providing FP services in Nigeria, there are still underlying factors discouraging the use of these services, and some of the factors are spousal's objection and lack of consent and communication [7] among other resilient factors. Women should be free to choose or deny FP services, including abortion or sterilization. Considering the low prevalence of contraceptives in Nigeria, there is a need to examine factors that can scale up the use [6]. Hence, it is imperative to examine the influence of spousal communication and attitude on FP use among young mothers in the peri-urban area of Osun State, Nigeria. The study aim was to identify and discuss how spousal's communication and attitude predict FP use among young mothers in the peri-urban area of Osun State, Nigeria.

\section{Methods}

Study design

A household-based cross-sectional study was conducted from September to December 2019 in three Osun state senatorial districts, Nigeria. Osun State has a total population of approximately 3.5 million. Females constitute about $48 \%$, according to the last census conducted in Nigeria [12]. The state has a TFR of 4.7 per woman of reproductive age as of 2016 [13].

\section{Population source}

This study comprises young mothers who had at least a child in the year preceding the survey between the age of 15 and 30 years old and were living in Osun West, Osun East and Osun Central senatorial districts in Osun State, Nigeria, during data collection. The study area was purposively chosen to capture male spousal influence, communication and attitude to FP use among this age group (because of high age-specific fertility rate as reported by the latest demographic and health survey conducted in Nigeria in the year 2018 [14].

\section{Inclusion criteria}

Women of reproductive age who were within the age group of 15-30 years currently living in the selected three senatorial districts of Osun State, Nigeria, who had at least a child in the year preceding the survey, were included in the study.

\section{Sample size}

Yamane's formula was used to estimate the sample size for this study. After considering the design effect and a $5 \%$ margin of error or nonresponse, the final estimated sample size was 420 .

\section{Sampling procedure}

A multistage sampling technique was used. All the three senatorial districts in Osun was considered in this study. Stratification of the peri-urban areas was done, and two areas were purposively selected within each senatorial district to help achieve the study's objective. House listing was done, then residential houses were randomly selected using the house listing numbers by the lottery method. Study participants were selected using a systematic random sampling method by counting the number of rooms in each house and using it as a sampling frame. According to the inclusion criteria, the first household in the sampling frame was selected, and all eligible respondents were interviewed for the study, followed by every other 3rd household in that order. This process was continued until the number of study 
JHR

36,4

676

participants was obtained from each house, but if there is no eligible respondent in the selected household, then the next household with eligible respondent was included.

\section{Variables}

The outcome variable for this study was contraceptive use among young mothers. Key independent variables include spousal's communication and attitude to FP use, while the covariate or control variables were the socio-demographic characteristics of the respondents, which include age, educational level, living arrangement, children ever born (CEB), family type, occupation status and monthly income. These variables were selected based on previous literature on FP use [15].

\section{Data collection}

Data were collected using an open data kit (ODK) phone application. A structured questionnaire with all the study objectives is designed and transcribed into a phone application using the ODK platform which was used for data collection while interviewing the respondents. This questionnaire was prepared and administered in English. To minimize the nonresponse, several visits were made if the respondent(s) is not available during the week; data collection was also done over the weekend.

A pretest or reliability test was done on $5 \%$ of the total sample size randomly selected young women in Obafemi Awolowo University, Osun State, Nigeria, before the actual time of data collection using the designed instrument (Mobile questionnaire). The pretest checked on the appropriateness, sequence, answerability of the questions and the reliability of the two key independent variables (Partners communication and attitude).

\section{Data analysis}

Participants' characteristics were summarized using frequency and percentages for all the variables. Firstly, chi-square $\left(\chi^{2}\right)$ analysis was done to determine the association between spousal's communication and attitude on FP use alongside the control variables, then binary logistic regression was done to identify how the key explanatory and control variables contributing to FP use among young mothers in the study. Variables with a $p$-value of less than 0.2 at bivariate analysis were entered into the final logistic regression model to control possible confounders. The odds ratio of the final model and their $95 \%$ confidence intervals were used as measures of association between the predictors and outcome variables. A $p$-value of less or equal to 0.05 was considered statistically significant. All analyses were performed using Stata 16 software.

\section{Operational definition of variables \\ Outcome variable}

The outcome variable, which is FP use among young mothers, was assessed by the question "if the respondent is currently using contraceptive" those who said, "yes" were coded " 1 " while those who said "no" were coded "0" [9].

\section{Key explanatory variables}

Spousal communication and spousal attitude during spousal communication were measured by 7 and 6 variables. For spousal communication, the following questions were asked about communication concerning money matters, the number of children, FP use, health, good nutrition, workload and medical checkup and possible responses were poor, fair and good. Those with index numbers from 5 and above were coded as "good", and those within 4-3 were 
coded as "fair," while those below 3 were coded "poor". Stata 16 software was used to combined and generate the index. The same procedure was used to measure spousal's attitude index where questions were asked about whether respondents' spousal listens, ask the question, respond appropriately, give advice/suggestions, show concerns/interest and expresses feelings during spousal communication. The responses were then grouped into poor, fair and good.

\section{Covariates}

Respondent socio-demographic characteristics, which are the control variable/co-variate, were assessed by the age of respondent, education level, religion, employment status, living arrangement, family type and children ever born. Spousal socio-demographics were assessed by spousal age, level of education, religion and employment status [9].

\section{Ethical considerations}

The research protocol was approved by the Research and Ethics committee of Institute of Public Health, Obafemi Awolowo University, Ile-Ife (IPH, OAU) with approval number HREC NO: IPHOAU/12/1446.

\section{Results}

Table 1 shows that more than half $(60 \%)$ of the respondent's age falls between 25 and 29 years and is followed by age group $20-24$ years $(23.6 \%)$ with an average age of 26 years. The

\begin{tabular}{|c|c|c|c|c|c|}
\hline Variable $N=420$ & Frequency & Percent & Variable & Frequency & $\%$ \\
\hline \multicolumn{3}{|c|}{ Respondent's age (years) } & \multicolumn{3}{|l|}{ Spouse's age } \\
\hline$<20$ years & 19 & 4.5 & $25-29$ & 96 & 22.9 \\
\hline 20-24 years & 99 & 23.6 & $30-34$ & 173 & 41.2 \\
\hline 25-29 years & 252 & 60.0 & $35-39$ & 110 & 26.2 \\
\hline $30+$ years & 50 & 11.9 & $40+$ & 41 & 9.7 \\
\hline \multicolumn{3}{|c|}{ Mean age: 26 years, SD: 3.4} & \multicolumn{3}{|c|}{ Mean age: 33 years, $S D: 5.4$} \\
\hline \multicolumn{3}{|c|}{ Respondent's level of education } & \multicolumn{3}{|c|}{ Spouse's level of education } \\
\hline No formal education & 15 & 3.7 & No formal education & 2 & 0.5 \\
\hline Primary & 44 & 10.4 & Primary & 9 & 2.1 \\
\hline Secondary & 177 & 42.1 & Secondary & 138 & 32.8 \\
\hline Postsecondary & 184 & 43.8 & Post-secondary & 271 & 64.5 \\
\hline \multicolumn{3}{|l|}{ Respondent's religion } & \multicolumn{3}{|l|}{ Spouse religion } \\
\hline Christianity & 279 & 66.4 & Christianity & 279 & 66.4 \\
\hline Islam & 139 & 33.1 & Islam & 141 & 33.6 \\
\hline Traditional & 2 & 0.5 & Traditional & 0 & 0.0 \\
\hline \multicolumn{3}{|c|}{ Respondent's occupation status } & \multicolumn{3}{|c|}{ Spouse's occupation status } \\
\hline Unemployed & 39 & 9.3 & Unemployed & 30 & 7.1 \\
\hline Employed & 381 & 90.7 & Employed & 390 & 92.9 \\
\hline \multicolumn{6}{|l|}{ Living arrangement } \\
\hline Living together & 338 & 80.5 & & & \\
\hline Living apart & 82 & 19.5 & & & \\
\hline \multicolumn{6}{|l|}{ Family type } \\
\hline Monogamous & 341 & 81.2 & & & \\
\hline Polygamous & 79 & 18.8 & & & \\
\hline \multicolumn{6}{|l|}{ Children ever born } \\
\hline $1-2$ years & 255 & 60.7 & & & \\
\hline $3+$ years & 165 & 39.3 & & & \\
\hline
\end{tabular}

\section{Family \\ planning use among young mothers}

\section{,}


JHR 36,4

\section{8}

respondents' education level shows that only $3.7 \%$ had no formal education, 10.4, 42.1 and $43.8 \%$ with primary, secondary and postsecondary.

About one third $(66.4 \%)$ of the respondents practice Christianity, while $33.1 \%$ and only $0.5 \%$ practice Islam and tradition. Almost all $(90.7 \%)$ of the respondents were employed; most $(80.5 \%)$ were living with their spouse. Regarding family type and the number of children ever born, most $(81.2 \%)$ of the respondent family type was monogamous and more than half $(60.7 \%)$ had one to two children.

Responses from respondents show that the average respondent's spouse age was 33 years distributed into age group as $25-29$ years $(22.9 \%)$, 30-34 years $(41.2 \%), 35-39$ years $(26.2 \%)$ and $40+(9.7 \%)$. One-third of the respondent's spouses had postsecondary education, followed by $32.8 \%$ with secondary, $2.1 \%$ with primary and only $0.5 \%$ with no formal education as their level of education. The same pattern was observed for respondent-spouse religion and occupation status with the respondent. About one third $(66.4 \%)$ of respondent spouse practice Christianity while the remaining $(33.6 \%)$ practice Islam, and almost all $(92.9 \%)$ were employed.

Table 2 shows that the majority of the respondent had good spousal communication concerning communication on money matters $(84.8 \%)$, the number of children $(72.9 \%)$, use of FP $(78.1 \%)$, health $(83.6 \%)$, good nutrition $(84.5 \%)$, workload $80.2 \%$ ) and medical checkup

\begin{tabular}{lrr}
\hline Variable $N=420$ & Frequency & $\%$ \\
\hline Communication on money matters & & \\
Poor & 64 & 15.2 \\
Good & 356 & 84.8 \\
Communication on the number of children & 114 & \\
Poor & 306 & 72.9 \\
Good & & \\
Communication on use of family planning & 92 & 21.9 \\
Poor & 328 & 78.1 \\
Good & & \\
Communication on respondent health & 69 & 16.4 \\
Poor & 351 & 83.6 \\
Good & & \\
Communication on good nutrition & 65 & 84.5 \\
Poor & 355 & \\
Good & & 80.8 \\
Communication on reducing respondent workload & 83 & \\
Poor & 337 & 28.3 \\
Good & & 71.7 \\
Communication on medical checkup & 119 & 18.3 \\
Poor & 301 & 12.1 \\
Good & & 30.5 \\
Communication index & 51 & 57.4 \\
Poor & 128 & 241 \\
Fair & 743 & \\
Good & & \\
No of family planning & & \\
Yes & & \\
& &
\end{tabular}

15.2

27.1

16.4

83.6

15.5

84.5

19.8

28.3
Table 2.

Spousal

communication and

use of family planning Yes 
(71.7\%). Concerning the communication index, more than half $(57.4 \%)$ of the respondents had good, $30.5 \%$ and $12.1 \%$ with fair and poor communication, respectively. The use of FP shows that most of the respondents were currently using an FP method.

Table 3 shows that the majority of the respondent's male spouse listens $(86.7 \%)$, ask a question $(81.7 \%)$, respond appropriately $(73.6 \%)$ and shows concerns/interest $(72.4 \%)$. More than half $(61.4 \%)$ gives advice/suggestion, and less than half $(49.5 \%)$ expresses their feeling during spousal communication. Concerning attitude index, $46.4,22.4$ and $31.2 \%$ fall in poor, fair and good attitude index categories, respectively.

Table 4 below shows a statistically significant relationship between spousal communication concerning communication on money matters, number of children, use of $\mathrm{FP}$, discussion about health, good nutrition, reducing respondent workload and medical checkup ( $($-value $<0.05)$. Also, there is a significant relationship between communication index and FP ( $\phi$-value $<0.05)$.

Table 5 presents a statistically significant relationship between respondent's male spouse attitude and respondent use of FP. The spouse listens to the respondent, asks questions, responds appropriately, shows concerns/interest and gives advice/suggestions $(\phi$-value $<0.05)$ during spousal communication. The attitude index also shows a statistically significant relationship with respondent use of $\mathrm{FP}(\phi$-value $<0.05)$.

Table 6 shows that respondents whose male spouse age falls into 30-34 years were more likely to use FP, and this is statistically significant in this study ( $p$-value $<0.05$ ). Respondents whose spouses were aged 40 years, or more were less likely to use FP, which is statistically significant in this study ( $\phi$-value $<0.05)$.

Respondents whose male spouses had postsecondary education and Islam as religion were more likely to use FP but not significant in this study. Respondents whose male

\begin{tabular}{|c|c|c|c|}
\hline Variable $N=420$ & Frequency & $\%$ & \\
\hline \multicolumn{4}{|c|}{ Listens to respondent } \\
\hline No & 56 & 13.3 & \\
\hline Yes & 364 & 86.7 & \\
\hline \multicolumn{4}{|l|}{ Ask question } \\
\hline No & 77 & 18.3 & \\
\hline Yes & 343 & 81.7 & \\
\hline \multicolumn{4}{|c|}{ Respond appropriately } \\
\hline No & 111 & 26.4 & \\
\hline Yes & 309 & 73.6 & \\
\hline \multicolumn{4}{|c|}{ Shows concern/interest } \\
\hline No & 116 & 27.6 & \\
\hline Yes & 304 & 72.4 & \\
\hline \multicolumn{4}{|c|}{ Gives advice/suggestion } \\
\hline No & 162 & 38.6 & \\
\hline Yes & 258 & 61.4 & \\
\hline \multicolumn{4}{|c|}{ Expresses his feelings } \\
\hline No & 212 & 50.5 & \\
\hline Yes & 208 & 49.5 & \\
\hline \multicolumn{3}{|l|}{ Attitude index } & $\begin{array}{l}\text { Table } 3 \text {. } \\
\text { Attitude of }\end{array}$ \\
\hline Poor & 195 & 46.4 & respondent's male \\
\hline Fair & 94 & 22.4 & spouse during \\
\hline Good & 131 & 31.2 & communication \\
\hline
\end{tabular}

\section{Family \\ planning use among young mothers}

679 


\begin{tabular}{|c|c|c|c|c|c|}
\hline \multirow{2}{*}{$\begin{array}{l}\text { JHR } \\
36,4\end{array}$} & \multirow{2}{*}{$\begin{array}{l}\text { Variable } N=420 \\
\text { Communication on money matters }\end{array}$} & \multirow[b]{2}{*}{ No $(n=77)$} & \multicolumn{2}{|c|}{ Use of family planning } & \multirow[b]{2}{*}{$\chi^{2} / p$-value } \\
\hline & & & Yes $(n=343)$ & Total & \\
\hline \multirow[b]{2}{*}{680} & $\begin{array}{l}\text { Poor } \\
\text { Good }\end{array}$ & $\begin{array}{l}55.8 \\
44.2\end{array}$ & $\begin{array}{r}6.1 \\
93.9\end{array}$ & $\begin{array}{l}15.2 \\
84.8\end{array}$ & $12036 / 000 *$ \\
\hline & $\begin{array}{l}\text { Communication on the number of } \mathrm{ch} \\
\text { Poor } \\
\text { Good }\end{array}$ & $\begin{array}{l}71.4 \\
28.6\end{array}$ & $\begin{array}{l}17.2 \\
82.8\end{array}$ & $\begin{array}{l}27.1 \\
72.9\end{array}$ & $93.51 / 0.00^{*}$ \\
\hline & $\begin{array}{l}\text { Communication on use of family pla } \\
\text { Poor } \\
\text { Good }\end{array}$ & $\begin{array}{l}70.1 \\
29.9\end{array}$ & $\begin{array}{l}11.1 \\
88.9\end{array}$ & $\begin{array}{l}21.9 \\
78.1\end{array}$ & $128.18 / 0.00^{*}$ \\
\hline & $\begin{array}{l}\text { Communication on respondent healt } \\
\text { Poor } \\
\text { Good }\end{array}$ & $\begin{array}{l}57.1 \\
42.9\end{array}$ & $\begin{array}{r}7.3 \\
92.7\end{array}$ & $\begin{array}{l}16.4 \\
83.6\end{array}$ & $113.84 / 0.00^{*}$ \\
\hline & $\begin{array}{l}\text { Communication on good nutrition } \\
\text { Poor } \\
\text { Good }\end{array}$ & $\begin{array}{l}52.0 \\
48.0\end{array}$ & $\begin{array}{r}7.3 \\
92.7\end{array}$ & $\begin{array}{l}15.5 \\
84.5\end{array}$ & $95.88 / 0.00 *$ \\
\hline & $\begin{array}{l}\text { Communication on reducing respond } \\
\text { Poor } \\
\text { Good }\end{array}$ & $\begin{array}{r}\text { vorkload } \\
54.5 \\
45.5\end{array}$ & $\begin{array}{l}12.0 \\
88.0\end{array}$ & $\begin{array}{l}19.8 \\
80.2\end{array}$ & $71.94 / 0.00^{*}$ \\
\hline $\begin{array}{l}\text { Table } 4 \text {. } \\
\text { Relationship between }\end{array}$ & $\begin{array}{l}\text { Communication on medical checkup } \\
\text { Poor } \\
\text { Good }\end{array}$ & $\begin{array}{l}59.7 \\
40.3\end{array}$ & $\begin{array}{l}21.3 \\
78.7\end{array}$ & $\begin{array}{l}28.3 \\
71.7\end{array}$ & $45.80 / 0.00 *$ \\
\hline $\begin{array}{l}\text { spousal } \\
\text { communication, } \\
\text { spousal } \\
\text { communication index } \\
\text { and use of FP }\end{array}$ & $\begin{array}{l}\text { Communication index } \\
\text { Poor } \\
\text { Fair } \\
\text { Good }\end{array}$ & $\begin{array}{l}45.5 \\
36.4 \\
18.1\end{array}$ & $\begin{array}{r}4.7 \\
29.2 \\
66.1\end{array}$ & $\begin{array}{l}12.1 \\
30.5 \\
57.4\end{array}$ & $112.48 / 0.00^{*}$ \\
\hline
\end{tabular}

spouses were employed were more likely to use FP, which is significant in this study $(p$-value $<0.05)$.

Concerning spousal communication index and attitude index, respondents with fair and good spousal communication and respondents whose male spouses had fair and good attitude index were more likely to use FP, which is statistically significant in this study ( $p$-value $<0.05$ ).

\section{Discussion}

This study examined the influence of spousal communication, attitude during spousal communication and use of $\mathrm{FP}$ among young mothers in peri-urban areas of Osun State. To the best of our knowledge, this is the first study in the study location.

The result showed that respondents whose spouse has good and fair communication during communication are more likely to use FP among young mothers residing in the peri-urban area of Osun State, Nigeria. This result is similar to the findings discovered in a study conducted in Ethiopia on spousal communication and modern FP use [16]. Various studies have documented that spousal communication can increase FP use and continuation $[4,16]$.

During spousal communication, the male spouse's attitude on FP use was significantly associated with FP use in this study as such women whose spouse has a good or fair attitude during communication were more likely to use FP. This is in line with a study conducted in Oyo State, Nigeria, that concluded that use of contraceptive by women is the mere attitude of 


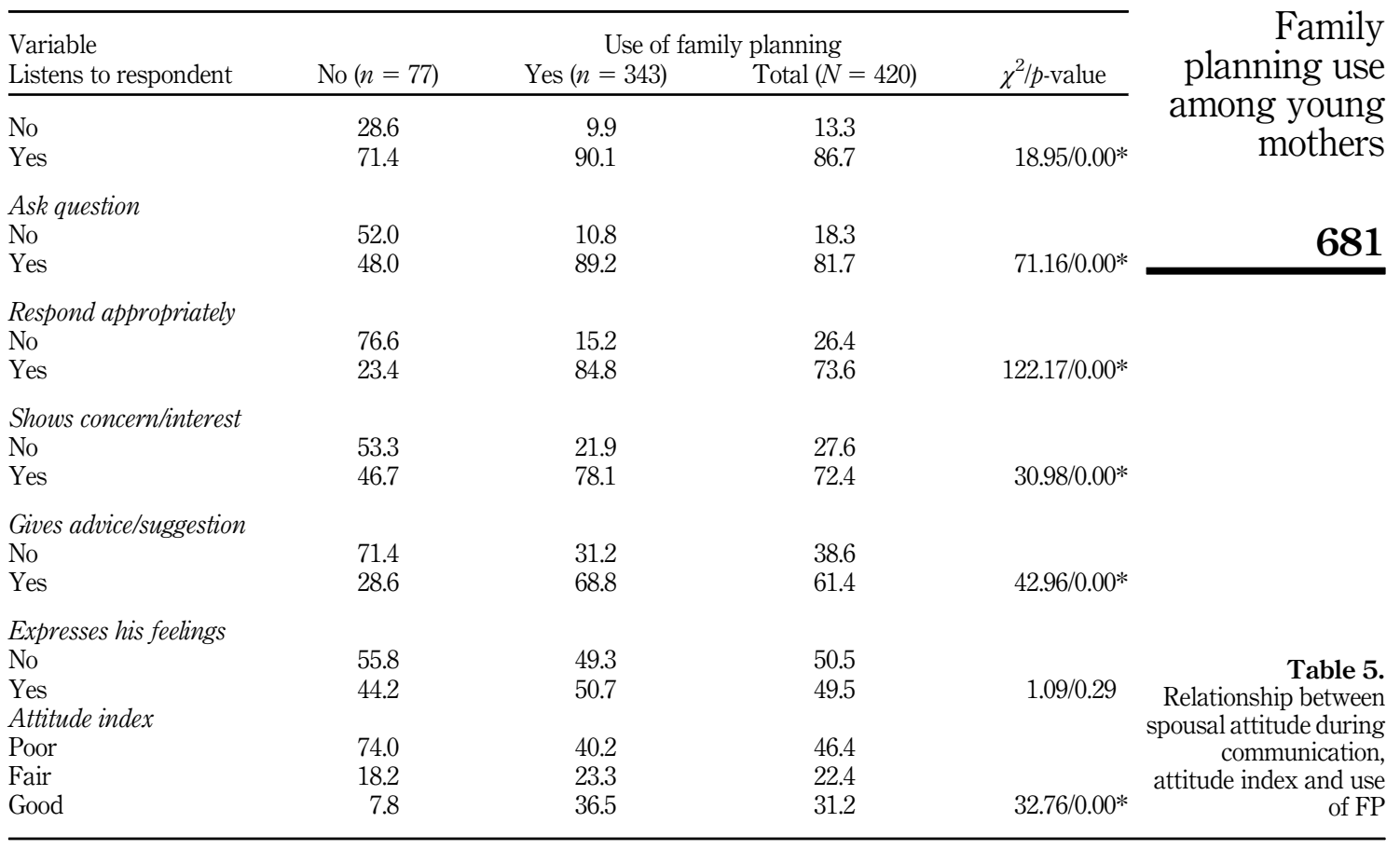

\begin{tabular}{|c|c|c|c|c|c|c|c|}
\hline \multirow{2}{*}{$\begin{array}{l}\text { Variable } \\
\text { Spouse age (RC: } 25-29)\end{array}$} & \multirow{2}{*}{ Odd ratio } & \multicolumn{2}{|c|}{ Unadjusted (cOR) } & \multicolumn{3}{|c|}{ Adjusted $(\mathrm{aOR})$} & \\
\hline & & $p$-value & $95 \% \mathrm{CI}$ & Odd ratio & $p$-value & $95 \% \mathrm{CI}$ & \\
\hline 30-34 years & 3.1 & $0.00 *$ & $1.42-6.74$ & 7.9 & $0.00 *$ & 2.30-26.72 & \\
\hline 35-39 years & 0.9 & 0.82 & $0.46-1.84$ & 2.7 & 0.07 & 0.92-7.93 & \\
\hline $40+$ years & 0.2 & $0.00^{*}$ & $0.06-0.33$ & 0.1 & $0.00 *$ & $0.02-0.23$ & \\
\hline \multicolumn{8}{|c|}{ Spouse level of education (RC: Primary) } \\
\hline Secondary & 1.7 & 0.43 & 0.46-6.09 & 0.7 & 0.71 & $0.10-4.78$ & \\
\hline Postsecondary & 3.5 & 0.05 & $0.9786-12.5443$ & 2.1 & 0.42 & $0.33-13.83$ & \\
\hline \multicolumn{8}{|l|}{ Religion (RC: Christian) } \\
\hline Islam & 1.0 & 0.97 & $0.59-1.67$ & 1.3 & 0.48 & $0.61-2.84$ & \\
\hline \multicolumn{8}{|c|}{ Spouse employment status (RC: Unemployed) } \\
\hline Employed & 32.5 & $0.00 *$ & $11.91-88.66$ & 7.2 & $0.00 *$ & $1.89-27.69$ & \\
\hline \multicolumn{8}{|c|}{ Communication index (RC: Poor) } \\
\hline Fair & 7.8 & $0.00 *$ & $3.78-16.13$ & 14.3 & $0.00 *$ & 4.57-44.62 & \\
\hline Good & 35.5 & $0.00 *$ & $15.93-78.99$ & 80.7 & $0.00 *$ & $19.80-328.84$ & Table 6. \\
\hline $\begin{array}{l}\text { Attitude index (RC: Poor) } \\
\text { Fair } \\
\text { Good }\end{array}$ & $\begin{array}{l}2.4 \\
8.6\end{array}$ & $\begin{array}{l}0.00^{*} \\
0.00^{*}\end{array}$ & $\begin{array}{c}1.23-4.50 \\
3.59-20.65\end{array}$ & $\begin{array}{l}0.8 \\
5.4\end{array}$ & $\begin{array}{l}0.73 \\
0.01 *\end{array}$ & $\begin{array}{l}0.29-2.36 \\
1.34-22.17\end{array}$ & $\begin{array}{l}\text { Multivariate logistic } \\
\text { regression of male } \\
\text { spousal characteristics, }\end{array}$ \\
\hline \multicolumn{7}{|c|}{$\begin{array}{l}\text { Note(s): *Statistically significant; CI: Confidence interval; cOR: Crude odd ratio; aOR: Adjusted odd ratio; RC: } \\
\text { Reference category }\end{array}$} & $\begin{array}{l}\text { communication index } \\
\text { and attitude index on } \\
\text { the family planning use }\end{array}$ \\
\hline
\end{tabular}


JHR

36,4

682

their male spouse, while the good or right attitude appraise the use of $\mathrm{FP}$ among women, wrong or poor attitude decrease the use or discourage the woman from using FP [2].

Respondents whose male spouse age is between 30 and 34 years were more likely to use FP than any other age group in the study. This may be because the respondents are beginning to understand the importance of spousal support on their decision-making, hence involving them in decision-making. Previous studies have also documented spousal age as a determinant factor in FP use $[17,18]$.

Lastly, the study's result showed that respondents whose male spouses have more than postsecondary education and are currently employed are more likely to use FP. Education has been seen as an avenue to widening one's knowledge on the pertinent issue as such, having higher education could be a propensity in the use of FP. Male spouses currently employed in the same vein are assumed to have a social life outside the home, which might have limited their sentiment on non-FP use. Studies conducted in Ghana [19] and Angola [11] also corroborate the study's result.

\section{Significance of the research}

Conducting a study on how spousal attitude and communication predict contraceptive use among young mothers in the peri-urban area of Osun State, Nigeria, is particularly relevant for policymakers since more information is needed about underlining factors that are significantly influencing the non/low use of FP in Nigeria and knowing these factors could contribute to the development of programs/interventions that are particularly relevant to increasing the use of FP in Nigeria.

\section{Strengths and limitations}

The study's strength is the ability to design questionnaires tailored toward the literature gap on nonuse of FP by young mothers. However, the study is without limitation because the focus was on young mothers alone why their spouses were not interviewed. Male spouse details were collected from the young mothers, and there may be inaccuracy in the reporting of male spouse social demographic characteristics used as a control variable in this study. Also, because this research was conducted among specific group, the results of the study cannot be used to generalize for another group.

\section{Conclusion}

The level of contraceptive use overall is low in Nigeria [20]. However, this study revealed a wide variation in spousal communication and attitude to FP use. We concluded that young mothers with good male spouse communication and attitude were more likely to use FP. Deliberate interventions which should include focus group discussion and community sensitization should be tailed toward encouraging good communication and attitude of male spouse toward their partner in the peri-urban area of Osun State, and by extension, the recommendations in this study can be applied anywhere in Nigeria with similar sociodemographic characteristics of the male spouse and young mother.

\section{Implications for future research and practice}

Future studies should consider both partners to harness the true picture of poor communication and attitude toward each other. The future study will also be more robust if it can consider a qualitative research design as this will help unveil more underlining factors influencing the nonuse of FP among young women.

Conflict of Interest: None 


\section{References}

1. Weinreb A. Family planning programs for the 21st century: rationale and design. Popul Stud. 2013; 67(3): 371-2. doi: 10.1080/00324728.2013.807018.

2. Olaoye T, Oluwatosin A, Ogunsanmi O, Ayodele KO. Male spouses' support of family planning (FP) uptake by wives: the role of socio-biographical mediators. J Health Med Nurs. 2015; 18: 86-96.

3. Grant C, Bhardwa M. Family planning communication. K4D Helpdesk Report. Brighton: Institute of Development Studies; 2016.

4. Ackerson K, Zielinski R. Factors influencing use of family planning in women living in crisis affected areas of Sub-Saharan Africa: a review of the literature. Midwifery. 2017; 54: 35-60. doi: 10. 1016/j.midw.2017.07.021.

5. Program for appropriate Technology in health [PATH]; United Nations population fund [UNFPA] Meeting the need: strengthening family planning programs. Seattle: PATH/UNFPA; 2006. Available at: https://www.unfpa.org/sites/default/files/resource-pdf/family_planning06.pdf.

6. Adegbola $\mathrm{O}$, Habeebu-Adeyemi FM. The influence of male partners on contraceptive usage in sub-Saharan Africa-Lagos experience. J Clin Sci. 2016; 13(3): 112-6. doi: 10.4103/2468-6859.185247.

7. Akaba G, Ketare N, Tile W. A community-based, mixed-methods study of the attitudes and behaviors of men regarding modern family planning in Nigeria. Int J Gynaecol Obstet. 2016; 135(1): 86-90. doi: 10.1016/j.ijgo.2016.04.009.

8. Sidze EM, Lardoux S, Speizer IS, Faye CM, Mutua MM, Badji F. Young women's access to and use of contraceptives: the role of providers' restrictions in urban Senegal. Int Perspect Sex Reprod Health. 2014; 40(4): 176-83. doi: 10.1363/4017614.

9. Yue K, O'Donnell C, Sparks PL. The effect of spousal communication on contraceptive use in Central Terai, Nepal. Patient Educ Couns. 2010; 81(3): 402-8. doi: 10.1016/j.pec.2010.07.018.

10. Amos M. Contraceptive method choice and spousal communication: examining the effect of family planning method using an instrumental variable approach. Sex Reprod Healthc. 2019; 22: 100458. doi: 10.1016/j.srhc.2019.100458.

11. Prata N, Bell S, Fraser A, Carvalho A, Neves I, Nieto-Andrade B. Partner support for family planning and modern contraceptive use in Luanda, Angola. Afr J Reprod Health. 2017; 21(2): 35-48. doi: 10.29063/ajrh2017/v21i2.5.

12. Federal Republic of Nigeria, National Population Commission. 2006 Population and housing census: priority table, volume III. Population distribution by sex, state, LGA and senatorial district. Abuja: National Population Commission; 2010.

13. Nigeria, National Bureau of Statistics [NBS]. Demographic statistics bulletin 2015. Abuja: NBS; 2016.

14. Nigeria, National Population Commission [NPC]; ICF. Nigeria demographic and health survey 2018. Abuja, Nigeria and Rockville, Maryland: NPC and ICF; 2019.

15. Bolarinwa OA, Olagunju OS. Knowledge and factors influencing long-acting reversible contraceptives use among women of reproductive age in Nigeria. Gates Open Res. 2019; 3: 7. doi: 10.12688/gatesopenres.12902.3.

16. Berhane A, Biadgilign S, Amberbir A, Morankar S, Berhane A, Deribe K. Men's knowledge and spousal communication about modern family planning methods in Ethiopia. Afr J Reprod Health. 2011; 15(4): 24-32.

17. Butto D, Mburu S. Factors associated with male involvement in family planning in West Pokot County, Kenya. Univers J Public Health. 2015; 3(4): 160-8. doi: 10.13189/ujph.2015.030404.

18. Kamal MM, Islam MS, Alam MS, Hasssn AE. Determinants of male involvement in family planning and reproductive health in Bangladesh. Am J Hum Ecol. 2013; 2(2): 83-93.

19. Manortey S, Missah K. Determinants of male involvement in family planning services: a case study in the Tema Metropolis, Ghana. Open Access Libr J. 2020; 7(1): e6043. doi: 10.4236/oalib. 1106043.

\section{Family \\ planning use among young mothers}

683 
20. Do M, Kurimoto N. Women's empowerment and choice of contraceptive methods in selected African countries. Int Perspect Sex Reprod Health. 2012; 38(1): 23-33. doi: 10.1363/3802312.

\section{Corresponding author}

Obasanjo Afolabi Bolarinwa can be contacted at: bolarinwaobasanjo@gmail.com

\section{4}

For instructions on how to order reprints of this article, please visit our website: www.emeraldgrouppublishing.com/licensing/reprints.htm Or contact us for further details: permissions@emeraldinsight.com 